\title{
Pandemia por el SARS-CoV-2: ¿Dónde reside el verdadero Armagedón?
}

\section{SARS-CoV-2 pandemic: Where does true Armagedon reside?}

\author{
Aland Bisso Andrade I
}

En 1918 ocurrió una pandemia por Influenza H1N1 de origen aviar que afectó a alrededor de 500 millones de personas (un $30 \%$ de la población mundial de aquel entonces) y una mortalidad global calculada en 50 millones, de los cuales 675,000 ocurrieron en los Estados Unidos.

En aquella época no se había aislado al virus, no se conocían con exactitud los factores de su propagación ni los mecanismos fisiopatológicos de la enfermedad y no existían exámenes de laboratorio para su diagnóstico. El lavado de manos y el uso de mascarillas y desinfectantes no obedecían a protocolos de seguridad bien definidos como hoy en día y tampoco eran tomados en cuenta con la seriedad y urgencia del caso. Los métodos para prevenir y tratar la influenza tenían limitaciones. No había vacunas contra la infección ni medicamentos antivirales, y tampoco existían antibióticos para tratar las infecciones bacterianas secundarias como la neumonía. Por último, los pacientes con insuficiencia respiratoria grave no tenían la chance de entrar al tipo de ventilación mecánica que se dispone hoy en día. Los esfuerzos para prevenir la propagación de la enfermedad se limitaban solo a la promoción de una buena higiene personal, el aislamiento, la cuarentena y el cierre de lugares públicos como escuelas y teatros. Presiento que después de más de 100 años algunas de aquellas bien fundadas recomendaciones no han variado a la fecha frente a la nueva pandemia por el ahora denominado SARSCoV-2. La diferencia fundamental, en contraste con lo que ocurrió en 1918, es que ahora el escenario es completamente diferente: la población mundial supera los seis mil millones de habitantes, el fenómeno de la globalización ha roto todas las fronteras, no sólo por el avance de la tecnología, sino

Médico internista. Past presidente de la SPMI
Bisso-Andrade, A Pandemia por el SARS-CoV-2: ¿Dónde reside el verdadero Armagedón?. Rev Soc Peru Med Interna. 2019;33(I):5-6. https://doi.org/10.36393/spmi.v33i1.502

que millones de personas se desplazan diariamente de un país a otro. Una movilización ilimitada de gente alrededor del mundo a la cual se suma el fenómeno migratorio debido a los serios conflictos que azotan muchas regiones del mundo. De otro lado, no todos los países tienen condiciones económicas y sanitarias en iguales condiciones. Sabemos de la precariedad del sistema de salud en los países en vías de desarrollo y de los exiguos presupuestos que sus gobiernos le asignan en este rubro. Además, un muy alto porcentaje de la población no tiene la educación ni el civismo adecuado para acatar las recomendaciones de las autoridades sanitarias y políticas.

Al 13 de marzo 2020, fecha en que escribo esta editorial, la gente acudía en masa a los centros comerciales para atiborrarse de papel higiénico, papel toalla, alimentos, lejía y jabones, aun cuando solo se habían notificado 38 casos definidos de SARS-CoV-2 y no había transmisión comunitaria bien establecida. Una situación insensata que solo lleva al desabastecimiento, especulación y una motivación para el vandalismo. Es decir, un caos social que solo puede empeorar la situación y generar más daño que la pandemia misma. Y eso, sin hablar de la compra desmedida de mascarillas y alcohol gel que ocurrió desde mucho antes, por más que todas las autoridades sanitarias y a través de todos los medios, dijeron que las mascarillas solo son útiles en pacientes sintomáticos y en el personal de salud expuesto, y que, más importante que el uso de alcohol, es el constante buen lavado de manos con agua y jabón. Sin duda, el temor a lo desconocido y las malas noticias que a diario viene de otras latitudes, pueden sacar lo peor del ser humano en este tipo de situaciones. El civismo, los valores, el amor al prójimo, el bien común y la solidaridad, no siempre estarán presente en la medida de lo deseado y hasta pueden convertirse en herramientas prescindibles en medio del caos. 
El nuevo escenario de hoy también muestra el alto nivel de información del que en todo momento podemos disponer. Sin embargo, por cada información veraz y confiable que encontramos en la Internet o las redes sociales, probablemente aparezcan diez (o mucho más) informaciones tergiversantes, falsas y anodinas. Al nuevo coronavirus se le han atribuido orígenes conspirativos, esotéricos, extraterrestres, entre muchos otros. Pero lo más peligroso reside en la información que circula respecto a su prevención y supuesto tratamiento. La lista es larga, va desde "sorbitos de agua caliente", ingesta de “ajos, limón, agua con sal" hasta un sinfín de vitaminas de todo tipo, energizantes, inmunoestimulantes, pócimas mágicas y oraciones especiales. El peligro de estas formulaciones difundidas en cada segundo que pasa, es que mucha gente las practica y hasta gasta dinero en forma innecesaria, descuidando la práctica de medidas de prevención científicamente comprobadas. Es probable que la acostumbrada baja credibilidad de la población por sus autoridades locales los lleve a creer más en lo que circula por las redes sociales que en los medios de comunicación oficiales o de instituciones científicas.

Por tanto, ¿cómo contener la diseminación de un nuevo virus en el escenario de nuestro tiempo? No estamos en 1918. Ahora conocemos al virus, existen los medios para su diagnóstico, contamos con tecnología médica sofisticada y podemos tener en tiempo real todo tipo de información. Sin embargo, en contrapeso, ahora existe una población desbordante que viaja por todo el mundo, en la mayoría de países el desarrollo sanitario no ha crecido a la velocidad de las necesidades de salud de la población, al mismo tiempo también deben lidiarse con otras endemias o epidemias, las brechas socioeconómicas son mayores, desconocemos la verdadera curva epidémica del nuevo virus (ojalá sea similar a la influenza) y aún no asoma la disposición de una droga antiviral eficaz y, menos, una vacuna.

Lo más probable que el comportamiento de la pandemia y tasa de mortalidad varíen de una región a otra. En China, aun cuando fue imposible detectar al paciente cero, su brutal medida de contención y enorme capacidad de respuesta sanitaria (construyeron un hospital en diez días), mostró una tasa de mortalidad de 2,3\% (1 023 fallecidos entre 44672 casos confirmados) y a la fecha han frenado significativamente la velocidad de aparición de casos nuevos. En Italia, la pandemia desbordó las medidas iniciales de contención (tardía y débil en opinión de muchos expertos) y rápidamente la diseminación se hizo comunitaria. En solo tres semanas (entre febrero y marzo de 2020) llegaron a la cifra de 21157 casos y 1441 fallecidos. Los casos graves han saturado su capacidad hospitalaria y la mortalidad general es alrededor del 6,5\%, atribuido, principalmente, a que su población tiene un muy alto porcentaje de adultos mayores ( $23 \%$ son mayores de 65 años), precisamente los más vulnerables a la infección por SARS-CoV-2. Por tanto, los países que tengan altas poblaciones de adultos mayores, con comorbilidades que los haga vulnerables, y al mismo tiempo no tengan acceso oportuno a los servicios de salud, tendrán, sin duda, las mayores tasas de mortalidad.

En este panorama, si bien es cierto solo queda por redoblar las medidas de contención y mantener una educación continua en la población, la cancha no está pareja para todos. No todos los países tienen la misma reserva económica y recursos para mantener por tiempo prolongado medidas como cierre de aeropuertos, toques de queda, suspensión de reuniones masivas y aislamientos. A la gente de a pie que sale a ganarse el pan de cada día y sin un centavo en el banco, no se le puede poner en cuarentena. Latinoamérica, África y varios países del sudeste asiático no están en condiciones de paralizar sus actividades comerciales por mucho tiempo, y sabemos de sobra que el colapso económico traería peores consecuencias que la misma pandemia. El mayor empobrecimiento de la población, simplemente, elevará la tasa de morbimortalidad por todas las otras patologías, sean o no transmisibles.

Entonces, ¿dónde reside el peligro de la aparición del verdadero Armagedón? ¿En el nuevo coronavirus? ¿En la capacidad de respuesta cívica de la población general? ¿En la inteligencia y honestidad de sus autoridades? ¿En el manejo inteligente y honesto de los recursos?

Son libres de añadir más interrogantes.

\section{REFERENCIAS BIBLIOGRÁFICAS}

1. Past pandemics. URL disponible en: https:/www.cdc.gov/flu/ pandemic-resources/basics/past-pandemics.html (Visto el 13 de marzo de 2020)

2. Zunyou $\mathrm{Wu}, \mathrm{McGoogan}$ J. Characteristics of and Important Lessons from the Coronavirus Disease 2019 (COVID-19) Outbreak in China. Summary of a Report of 72314 Cases from the Chinese Center for Disease Control and Prevention. JAMA. Published online February 24, 2020.

3. Ebrahim SH, Memish ZA. COVID-19 - the role of mass gatherings. Travel Med Infect Dis. 2020 Mar 9: 101617.

4. Italy: Coronavirus cases. URL disponible en: https://www. worldometers.info/coronavirus/country/italy/ (Visto el 14 de marzo de 2020) 